\title{
Structure and Radiation Properties of Large-scale Natural Gas/Air Diffusion Flames
}

\author{
J. P. Gore and G. M. Faeth \\ Department of Aerospace Engineering, The University of Michigan, Ann Arbor, Michigan 48109, USA \\ D. Evans \\ Center for Fire Research, National Bureau of Standards, Gaithersburg, Maryland 20899, USA \\ and \\ D. B. Pfenning \\ Energy Analysts, Inc., Norman, Oklahoma 73069, USA
}

\begin{abstract}
Recent data from large-scale turbulent natural gas/air diffusion flames (135-210 MW) were used to evaluate analysis of flame structure and radiation properties. The conserved-scalar formalism, in conjunction with the laminar flamelet concept, was used to estimate flame structure. The discrete-transfer method, in conjunction with a narrow-band radiation model, was used to predict radiative heat fluxes. The narrow-band model considered the nonluminous gas bands of water vapor, carbon dioxide, methane and carbon monoxide in the 1000-6000 $\mathrm{nm}$ wavelength range. Structure predictions were encouraging, with discrepancies for mean temperatures ( $\mathrm{ca} 200 \mathrm{~K}$ in the hottest portions of the flames) comparable to experimental uncertainties, due to thermocouple errors, flame disturbances from ambient winds and lifting and external expansion effects near the injector. Radiative heat flux predictions were also reasonably good, e.g. predictions based on mean scalar properties were generally $15 \%$ lower than the measurements. The findings also suggest that continuum radiation from soot is negligible for these flames.
\end{abstract}

\section{INTRODUCTION}

Radiation from turbulent diffusion flames dominates energy transport from unwanted fires, influencing their burning and growth rates. Flame radiation is also a serious hazard to personnel and equipment during fires resulting from blowout of oil and gas wells, even though these fires do not spread in the conventional sense. Furthermore, the design of industrial flares involves consideration of flame radiation properties for similar reasons. Motivated by these problems, the present study considers the structure and radiation properties of largescale turbulent diffusion flames.

Several recent studies have considered the structure and radiation properties of laboratory-scale turbulent diffusion flames (flame heights $c a 1 \mathrm{~m}$ ). ${ }^{1-9}$ Methods for predicting flame structure and radiative heat fluxes were evaluated using measurements for vertically-upward fuel flow in still air. The following fuels were considered: methane, ${ }^{1-4}$ propane, ${ }^{5}$ carbon monoxide, ${ }^{6}$ hydrogen, ${ }^{7}$ ethylene $^{8}$ and acetylene. ${ }^{9}$ Predictions of structure and radiation properties were encouraging for these laboratory-scale flames; however, the potential of these methods has not been evaluated for large-scale flames which are often encountered in practice.

The objective of the present investigation was to remove this deficiency by using data recently obtained from large-scale turbulent diffusion flames ${ }^{10,11}$ to evaluate structure and radiation predictions. The measurements involved vertically-upward injection of natural gas $(96 \%$ methane by volume) in still air. Seven flames were tested (flame heights $c a 25 \mathrm{~m}$ ) with chemical energy release rates in the range of 135-210 MW. Measurements were made of mean temperatures and radiative heat fluxes, providing a reasonable data base to evaluate both structure and radiation predictions.

The paper begins with a description of the measurements. This is followed by a summary of theoretical methods used to compute flame structure and radiative heat fluxes. Auxiliary measurements in laminar flames, used to find the relationship between the extent of mixing and scalar properties, are then described. The paper concludes with a comparison between predictions and measurements for the turbulent flames. The present discussion is brief, and further details concerning theory and experiments (including a complete tabulation of data) are provided by Gore ${ }^{9}$ and Pfenning. ${ }^{11}$

\section{MEASUREMENTS}

\section{Test arrangements}

The general character of the large-scale flames can be seen from Fig. 1. The scale of the flames can be measured by noting that the instrument mast at the left-hand side of Fig. 1 is $24.4 \mathrm{~m}$ high. The lower third of the visible portion of the flame is blue while the remainder is yellow, which is very similar to the appearance of laboratory-scale natural gas/air diffusion flames. ${ }^{1-4,9}$ While the yellow color suggests potential continuum radiation from soot, measurements in the laboratory flames showed that continuum radiation in the infrared was negligible. ${ }^{1-4}$ Evidence from the present study, to be discussed later, leads to a similar conclusion for the large-scale flames.

The composition of the natural gas used for the largescale flames is summarized in Table 1. The gas composition used during the earlier laboratory tests, ${ }^{1-4}$ as well 


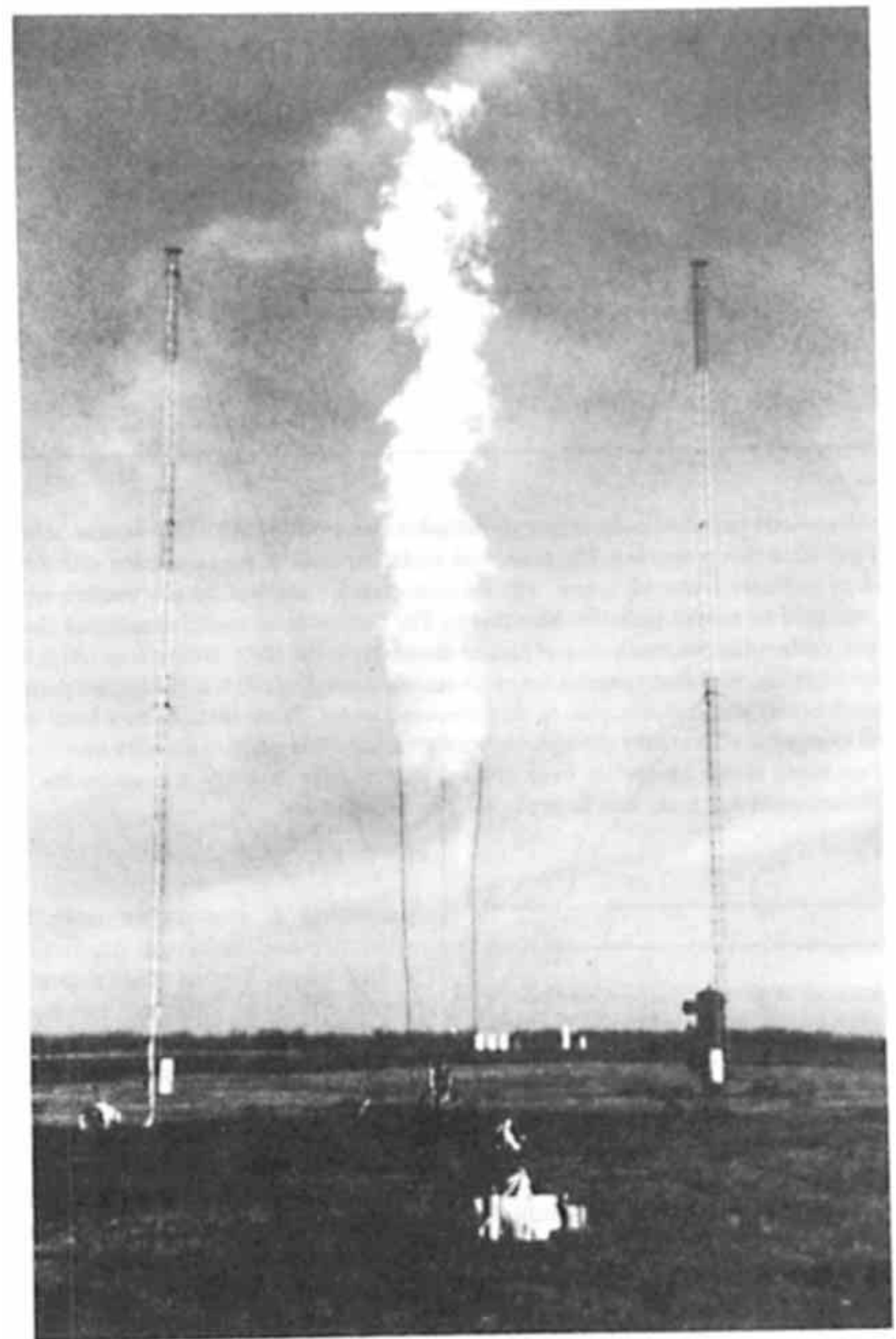

Figure 1. Photograph of a typical turbulent natural gas/air diffusion flame.

Table 1. Test gas composition

Component

Methane

Ethane

Propane

$\mathrm{C}_{4}$ hydrocarbons

$\mathrm{C}_{5}$ hydrocarbons

$\mathrm{C}_{6}$ hydrocarbons

and above

Nitrogen

Carbon dioxide

Other
Composition (\% molar)

\begin{tabular}{cc}
\multicolumn{2}{c}{ Composition (\% molar) } \\
\hline Turbulent flames & Laminar flames \\
96.35 & 94.86 \\
1.58 & 3.75 \\
0.28 & 0.27 \\
0.10 & 0.09 \\
0.02 & 0.04 \\
0.02 & \\
1.39 & 0.08 \\
0.26 & 0.41 \\
- & 0.42 \\
& 0.08
\end{tabular}

as for auxiliary laminar-flame tests during the present study, is also summarized in the table. The natural gas composition in both instances was similar, comprising roughly $95 \%$ methane by volume.

The arrangement of the test facility for the large-scale flames is illustrated in Fig. 2. The burner exit was directed vertically upward at a height of $1.5 \mathrm{~m}$ above the ground. Two different burners were used, involving uncooled restriction orifices having diameters of 76 and $102 \mathrm{~mm}$. Gas was supplied from ten high-pressure cylinders, through a manifold, a metering orifice plate and a $152 \mathrm{~mm}$ diameter line to the burner exit. The flames were ignited with a pilot flame which was turned off after ignition. The flames stabilized naturally at the burner exit; however, 


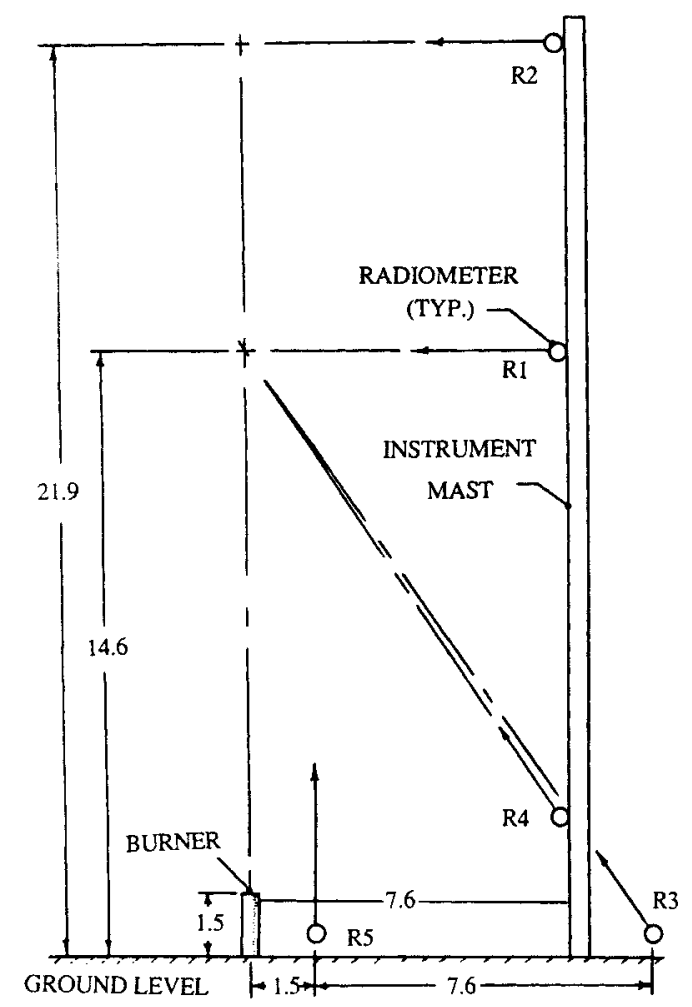

Figure 2. Diagram of the test arrangement (dimensions in metres).

they were generally lifted $15-20$ injector diameters. Nevertheless, the degree of premixing was not very large, as evidenced by temperature profiles and flame lengths; therefore they were treated as diffusion flames during analysis.

Pressures and temperatures just upstream of the restriction orifice were measured continuously. Local wind direction and speed, and the ambient wet- and dry-bulb temperatures were measured at a height of $9.1 \mathrm{~m}$ above the ground.

\section{Instrumentation}

Measurements involved an array of twenty thermocouples and five radiative heat flux transducers. The thermocouple array was supported by two $24.4 \mathrm{~m}$ high towers, spaced $15.3 \mathrm{~m}$ apart on a plane through the flame axis. Chromel/alumel (type K) thermocouples, having spherical junctions with diameters of roughly $0.5 \mathrm{~mm}$, were used. Velocities were not measured in the flames and thermocouple surface emissivity properties were not calibrated; therefore, an accurate estimate of radiation errors cannot be made. Estimates based on computed velocities, using emissivities based on laboratory tests, suggest that measured mean temperatures are $c a 100 \mathrm{~K}$ too low in the high-temperature portions of the flames.

Five water-cooled Medtherm heat flux transducers (Series 64), fitted with sapphire windows, were used to measure radiative heat fluxes. Their positions and orientations are illustrated in Fig. 2. Radiometer 1 had a $7^{\circ}$ viewing cone; the remainder had $150^{\circ}$ viewing cones. Radiometer 3 was placed slightly outside the instrument plane so that its field of view just missed the instrument support tower. The optical axes of the remaining radiometers were in the instrument plane. The time of day for testing and the orientation of the radiometers were chosen to minimize background from solar radiation.

\section{Test conditions}

The tests were conducted primarily to evaluate methods for extinguishing well blow-out fires with water. ${ }^{10}$ The gas was ignited with a pilot flame (which was then turned off) and the flames were allowed to stabilize before initiating the water extinguishing system. Data for present purposes were obtained just before the water flow was initiated, e.g. 12-40s after ignition.

The properties of the seven test flames are summarized in Table 2 (all nomenclature is defined at the end of this paper). Flames 1 and 7 used the $76 \mathrm{~mm}$ diameter burner, while the remaining flames used the $102 \mathrm{~mm}$ diameter burner. Burner exit Reynolds numbers were roughly $3 \times 10^{6}$, yielding highly turbulent flows with relatively small effects of buoyancy over the visible portion of the flames. Ambient wind speeds were in the range 0.2 $-2.1 \mathrm{~m} / \mathrm{s}$, being highest for Flames 1,2 and 3 . The wind disturbances deflected the flames from their geometrical axis, toward the heat flux sensor array, and are probably the largest source of experimental uncertainty. Unfortunately, uncertainties from these disturbances are difficult to quantify.

Stagnation temperatures upstream of the restriction orifice were lower than ambient ones due to the rapid expansion of gas in the supply tanks as the fuel was consumed. Stagnation pressures upstream of the restriction orifice were significantly greater than twice the ambient pressure; therefore the flow at the burner exit corresponds to an underexpanded sonic jet. This introduces an external expansion region, involving a system of

\begin{tabular}{|c|c|c|c|c|c|c|c|c|c|c|}
\hline Flame & $\begin{array}{c}d \\
(\mathrm{~mm})\end{array}$ & $\begin{array}{c}0 \\
(M W)\end{array}$ & $\begin{array}{c}m \\
\left(\mathrm{~kg} \mathrm{~s}^{-1}\right)\end{array}$ & $\begin{array}{c}R e \\
\left(\times 10^{-6}\right)\end{array}$ & $\begin{array}{c}u_{\infty} \\
\left(m s^{-1}\right)\end{array}$ & $\begin{array}{l}I^{0} \\
(\mathrm{~K})\end{array}$ & $\begin{array}{c}\rho^{0} \\
(\mathrm{KP} \text { Pa) }\end{array}$ & $\begin{array}{c}u_{e}^{\prime} \\
\left(\mathrm{ms}^{-1}\right)\end{array}$ & $\begin{array}{c}d_{e} \\
(\mathrm{~mm})\end{array}$ & $\begin{array}{c}u_{e} \\
\left(m s^{-1}\right)\end{array}$ \\
\hline 1 & 76 & 135 & 2.69 & 2.8 & $0.9-2.0$ & 259 & 424 & 610 & 86 & 572 \\
\hline 2 & 102 & 210 & 4.20 & 3.4 & $1.1-2.1$ & 249 & 352 & 558 & 110 & 529 \\
\hline 3 & 102 & 207 & 4.14 & 3.5 & $1.3-1.8$ & 256 & 349 & 562 & 110 & 533 \\
\hline 4 & 102 & 192 & 3.83 & 3.5 & $0.4-0.5$ & 272 & 331 & 567 & 109 & 540 \\
\hline 5 & 102 & 187 & 3.74 & 3.3 & $0.2-0.5$ & 263 & 305 & 534 & 107 & 515 \\
\hline 6 & 102 & 174 & 3.47 & 3.2 & $0.6-0.7$ & 252 & 287 & 514 & 106 & 491 \\
\hline 7 & 76 & 147 & 2.93 & 2.6 & $0.8-0.9$ & 242 & 418 & 574 & 86 & 550 \\
\hline
\end{tabular}

avertically upward injection, injector exit $1.52 \mathrm{~m}$ above ground, ambient temperature $285 \mathrm{~K}$ (Flame 1), $279 \mathrm{~K}$ (Flames 2-7). 
shock waves and supersonic flow, as the flow expands to the ambient pressure near the burner exit. Rather than attempt computations of the complex external expansion region, equivalent fully expanded exit conditions were defined, similar to past work. ${ }^{12-15}$ Computation of equivalent conditions will be described later; values used appear in the last three columns of Table 2.

\section{THEORETICAL METHODS}

\section{Flame structure}

Analysis of flame structure was similar to past work. ${ }^{1-8}$ The conserved-scalar method was used, in conjunction with a $k-\varepsilon-g$ model of turbulence. Major assumptions were as follows:

(1) Boundary-layer approximations apply for an axisymmetric flame with no swirl;

(2) Equal exchange coefficients of all species and heat;

(3) Negligible radiative heat loss to the surroundings and radiant exchange within the flames;

(4) Buoyancy only affects the mean flow;

(5) Negligible mean kinetic energy; and

(6) Static pressure variation only due to hydrostatic effects.

The first assumption is a condition of the experiments. Assumptions (2)-(4) have been successfully used during past analysis of natural gas diffusion flames and their justification is presented elsewhere. ${ }^{1-4}$ Since the present burners operated with sonic exit conditions, kinetic energies were significant near the burner exit. However, levels of kinetic energy are still small in comparison with a sensible energy changes due to combustion; therefore, assumption (5) is reasonably justified for present conditions. Assumption (6) is not formally justified due to presence of the external expansion region. However, this is circumvented by the use of equivalent initial conditions to be discussed later.

The mass-weighted (Favre) averaged formulation of Bilger $^{16}$ was adopted, but differing in some details. This involves solution of governing equations for conservation of mass, momentum and mixture fraction in the mean, and modeled governing equations for the turbulence quantities $k, \varepsilon$ and $g$. The conserved scalar is mixture fraction, which is the fraction of mass at a point that originated from the burner. Empirical constants in the turbulence model were established by calibration with measurements from constant- and variable-density noncombusting jets. ${ }^{2}$ The constants used, however, are not very different from an early proposal by Lockwood and Naguib. ${ }^{7}$

The laminar-flamelet approximation was used to relate scalar properties to the mixture fraction, following Bilger. ${ }^{18}$ This implies that scalar properties are only a function of mixture fraction, termed the 'state relationships'. State relationships for the concentrations of major gas species were found by auxiliary measurements in laminar flames, to be described later. These relationships for density and temperature were then computed, using the measured compositions and assuming negligible heat loss by radiation. Thermochemical properties for these computations were obtained from Gordon and McBride. ${ }^{19}$

\section{Initial conditions}

The external expansion region has not been studied very much, limiting capabilities to treat this flow exactly. Therefore detailed analysis of the near-injector region was avoided by seeking an equivalent initial condition having a static pressure equal to the ambient pressure, following past work. ${ }^{12-15}$ This approximation is justified, since the external expansion region is relatively short in comparison with the strongly radiating region of the flames. e.g. ca 5 jet exit diameters as opposed to $100-150$ jet exit diameters. Furthermore, the scalar structure of turbulent diffusion flames is relatively independent of burner exit velocities for the present high Reynolds number flames. ${ }^{1-4}$

Two methods were used to establish equivalent initial conditions, as follows: (1) a divergent-nozzle approximation and (2) a momentum-velocity approximation. The divergent-nozzle approximation has been used before. ${ }^{12-14}$ In this case, the flow near the jet exit is approximated by an isentropic one-dimensional expansion to the ambient pressure, e.g. the equivalent flow is the same as in the divergent or supersonic portion of a convergent/divergent nozzle. This defines an equivalent exit diameter, velocity and scalar state at the virtual origin of the flow (taken to be the actual jet exit for present calculations). The resulting equivalent diameters and velocities, denoted $d_{\mathrm{e}}$ and $u_{\mathrm{e}}$, are summarized in Table 2. Since kinetic energy effects were neglected in the analysis, the equivalent scalar state was taken at the stagnation temperature and static pressure.

The momentum-velocity method uses the actual jet diameter and an equivalent velocity which preserves the momentum of the flow. This velocity is computed as follows:

$$
u_{\mathrm{e}}^{\prime}=u_{\mathrm{o}}+\left(p_{\mathrm{o}}-p_{\infty}\right) / G_{\mathrm{o}}
$$

where $u_{\mathrm{o}}, p_{\mathrm{o}}$ and $G_{\mathrm{o}}$ were computed assuming isentropic flow from the stagnation state to sonic conditions at the burner exit, for a flow coefficient of unity. The second term on the right-hand side of Eqn (1) is the atmospheric correction, e.g. the increase in momentum of the flow since the local static pressure is higher than ambient. Values of $u_{\mathrm{e}}^{\prime}$ are also summarized in Table 2 .

\section{Spectral radiation intensities}

Radiative heat fluxes were found by summing spectral radiation intensities over wavelength and paths through the flame (covering the field of view of the heat flux sensors), following Jeng and coworkers. ${ }^{3,5}$ The equation of radiative transfer was solved for each path to find the spectral radiation intensities. The Goody statistical narrow-band model, employing the Curtis-Godson approximation for an inhomogeneous path, was used for these calculations, following Ludwig et al. ${ }^{20}$ The computer algorithm RADCAL, developed by Grosshandler, ${ }^{23}$ was used for the computations.

Past work suggested that radiation in natural gas/air diffusion flames is largely due to the non-luminous gas 
bands in the $1000-6000 \mathrm{~nm}$ wavelength range; therefore present computations were limited to this region. The following bands were considered: the $1140,1380,1870$, 2700 and $6300 \mathrm{~nm}$ bands of water vapor; the 2700 and $4300 \mathrm{~nm}$ bands of carbon dioxide; the 2300 and $3300 \mathrm{~nm}$ bands of methane; and the $4700 \mathrm{~nm}$ band of carbon monoxide. The diatomic gases (nitrogen, oxygen and hydrogen) are negligible contributors to flame radiation at all concentrations. ${ }^{3}$ The concentrations of other species are too small to provide significant radiation effects. As noted earlier, continuum radiation from soot in natural gas/air flames is negligible for laboratory conditions, even though the upper reaches of the flames are yellow. ${ }^{3}$ Based on this observation, continuum radiation from soot was ignored for the large-scale flames as well. Effects of scattering from gases are small in the infrared, and were ignored with little error. ${ }^{3}$

Turbulence/radiation interactions were ignored during the calculations, since this effect was found to be small for laboratory size natural gas/air diffusion flames. ${ }^{3}$ This implies use of time-averaged scalar properties along each path. This was checked by carrying out a few calculations of spectral radiation intensities using a stochastic method developed earlier. ${ }^{1-8}$

The stochastic approach involves dividing each gas path into discrete eddies having uniform properties and dimensions equal to the local dissipation length scale. Solution of the governing equations provides the timeaveraged probability density function of mixture fraction for each eddy. The probability density functions are randomly sampled to find mixture fractions and thus the scalar properties from the state relationships, for each eddy. These properties are then used to compute spectral intensities for this realization of the flow. Sampling and calculations continue in this manner until a sufficient number of realizations have been considered to compute statistically significant time-averaged spectral intensities.

\section{Radiative heat fluxes}

Radiative heat fluxes were computed using the discrete transfer method of Lockwood and Shah. ${ }^{22}$ This involves summing intensities over wavelength and paths through the flame to the radiative heat flux detectors ( 120 paths to cover the field of view of each detector). Richardson extrapolation suggests that the overall discretization errors in the radiative heat flux calculations are less than $10^{\circ} \%$. The wavelength range, $1000-6000 \mathrm{~nm}$, covers all significant gas bands, since the sapphire windows on the heat flux detectors are opaque to radiation beyond $6000 \mathrm{~nm}$. As noted earlier, these computations were based on mean scalar properties (the mean-property method).

\section{RESULTS AND DISCUSSION}

\section{State relationships}

Bilger ${ }^{18}$ has pointed out that scalar properties in laminar diffusion flames are primarily a function of mixture fraction, relatively independent of local velocities and position (flame stretch) except for relatively small regions where the flame is attached. The laminar flamelet concept then implies that these functions, called state relationships, are the same for turbulent flames, i.e. turbulent flames have scalar properties equivalent to wrinkled laminar flames.

The laminar flamelet concept was tested for methane/air diffusion flames by Jeng and Faeth. ${ }^{2}$ It was found that laminar flame data for a variety of configurations, operating conditions and positions in the flames (using data obtained from Tsuji and Yamaska ${ }^{23-5}$ and Mitchell et al. ${ }^{26}$ ) yielded universal correlations of scalar properties as a function of mixture fraction. Furthermore, state relationships based on these correlations yielded reasonably good predictions of the scalar structure of laboratory-scale turbulent methane/air diffusion flames.

The laminar flamelet concept was tested directly for natural gas/air diffusion flames during this investigation. Properties of the fuel used during these tests, listed in Table 1, are similar to the fuel used for the large-scale flames. The fuel was burned in a laminar flame configuration involving a $14.3 \mathrm{~mm}$ diameter fuel jet surrounded by coflowing air from a $102 \mathrm{~mm}$ diameter duct. Gas compositions were measured by sampling with a quartz microprobe, followed by analysis with a gas chromatograph, similar to past practice. ${ }^{6-9}$

Laminar flame measurements of the concentrations of nitrogen, methane, oxygen, carbon monoxide, water vapor and hydrogen are plotted as a function of local fuel-equivalence ratio (which is a single-valued function of mixture fraction) in Figs 3 and 4 . The measurements include a variety of positions and burner flow rates. Positions are only distinguished by height above the burner, to reduce cluttering of the figures. The fuel-equivalence ratios of the samples were based on their carbon and oxygen content, assuming that the carbon/hydrogen ratio of the fuel was constant at each point in the flow. Concentration predictions assuming

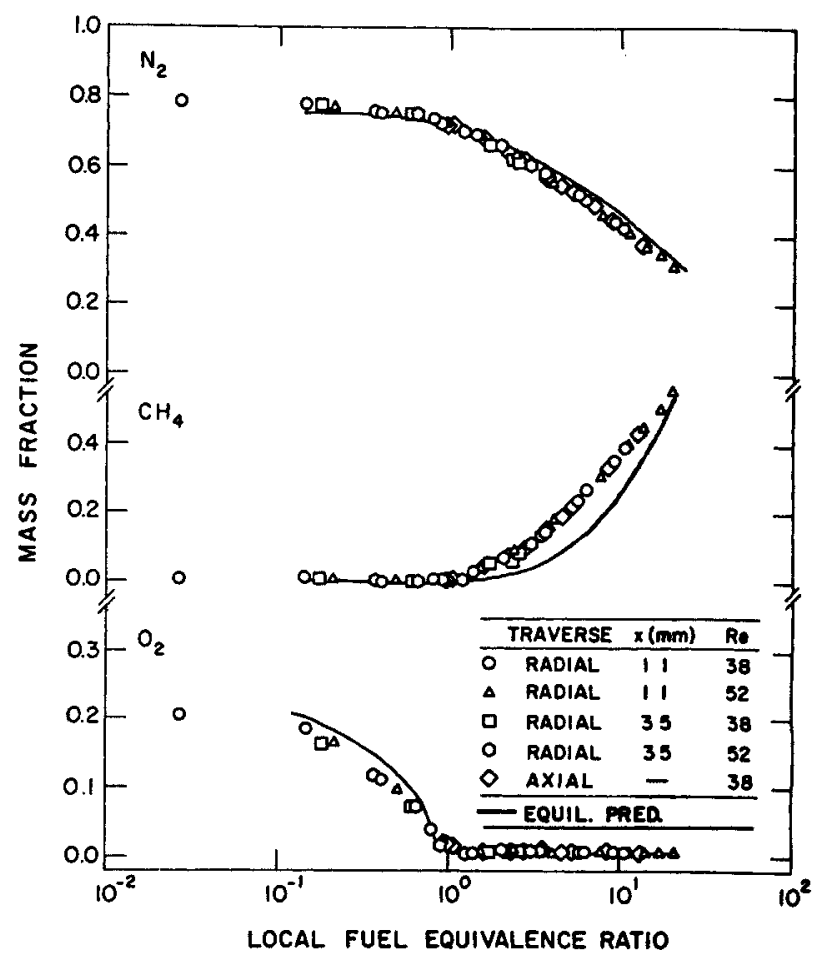

Figure 3. Natural gas/air diffusion flame state relationships. 


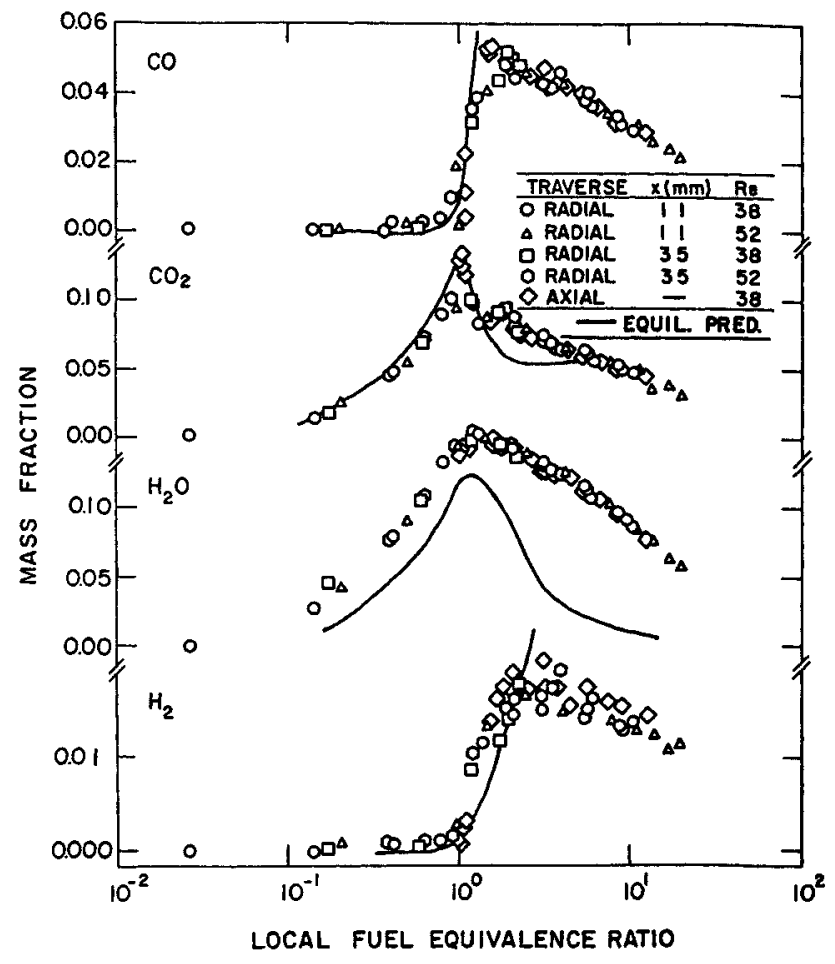

Figure 4. Natural gas/air diffusion flame state relationships (continued).

adiabatic combustion and local thermodynamic equilibrium are also shown on the plots for comparison with the measurements. These predictions were obtained using the Gordon and McBride ${ }^{19}$ algorithm, omitting the presence of solid carbon.

The results illustrated in Figs 3 and 4 are similar to earlier findings for laminar methane/air diffusion flames. ${ }^{2}$ The measurements approximate local thermodynamic equilibrium for lean conditions, but depart appreciably from equilibrium for fuel-rich conditions. However, the departure from equilibrium is reasonably universal, supporting the laminar flamelet hypothesis. Correlations of the data illustrated in Figs 3 and 4 were adopted for the state relationships used during present flame structure computations. However, these results are essentially the same as the earlier work of Jeng and Faeth. ${ }^{2}$

\section{Flame structure}

Structure measurements were divided into two groups (cf. Table 2) as follows: (1) Flames 1 and 7 using a $76 \mathrm{~mm}$ diameter burner, denoted $100 \mathrm{MW}$ flames; and (2) Flames 2-6 using a $102 \mathrm{~mm}$ diameter burner, denoted $200 \mathrm{MW}$ flames. Variation of initial conditions within these groups did not cause significant changes in predictions; therefore averages of initial conditions for each group are used to obtain predictions for the entire group in the following.

Predicted and measured mean temperatures along the axis are illustrated for the two flame groups in Figs 5 and 6. Separate predictions are shown for the divergent-nozzle and momentum-velocity methods of specifying equivalent initial conditions. In each case, both time- and density-weighted (Favre)-averaged predictions of mean temperature are shown. The degree of density weighting of the measurements is unknown; however, predicted differences between these averages are not very large. Differences between the two methods used to select equivalent initial conditions are also not very significant. The divergent-nozzle method uses a larger initial diameter which causes the maximum temperature position along the axis to shift somewhat downstream, e.g. high Reynolds number jet flames tend to scale with initial jet diameter but their scalar structure is relatively independent of initial jet velocities.

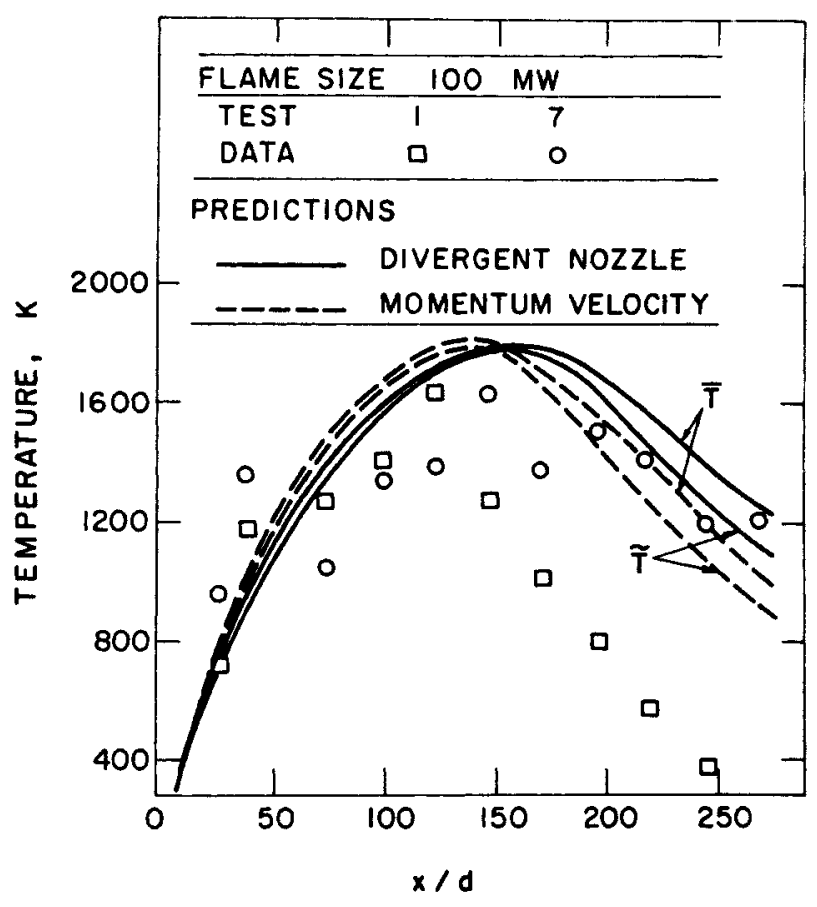

Figure 5. Predicted and measured mean temperatures along the axis of $100 \mathrm{MW}$ flames.

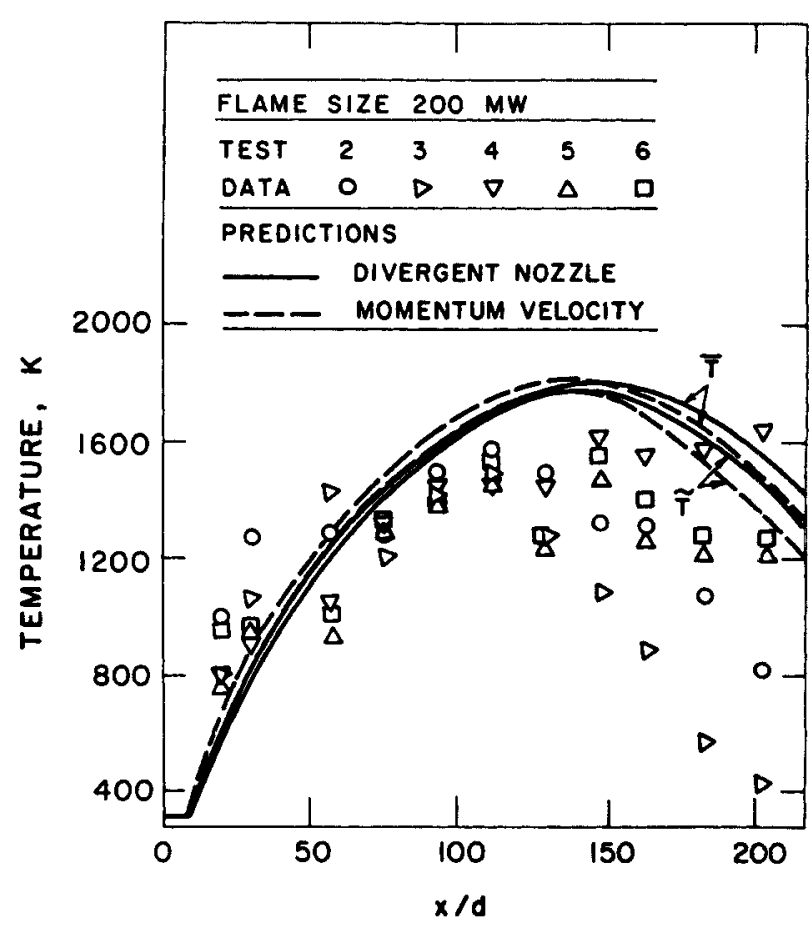

Figure 6. Predicted and measured mean temperatures along the axis of $200 \mathrm{MW}$ flames. 
Except for the near-injector region, the comparison between predictions and measurements in Figs 5 and 6 is poorest for Flames 1, 2, and 3. This behavior is probably due to ambient wind disturbances, which were highest for these flames (cf. Table 2). Wind disturbances deflected the axis of the flame, causing measured temperatures to be too low, particularly at locations far from the burner exit. The comparison between predictions and measurements for the remaining flames, however, is more encouraging. Measured maximum temperatures are roughly $200 \mathrm{~K}$ below the predictions, which is reasonable in view of thermocouple radiation errors and probable effects of wind disturbances. While the comparison between predictions and measurements is less satisfactory than for wellcontrolled laboratory conditions, probably due to wind disturbances, and effects of lifted flames, the structure analysis appears sufficiently adequate to proceed with evaluation of radiation predictions. These results are considered next.

\section{Flame radiation}

Before proceeding with the large-scale flames, present spectral intensity predictions were checked using a laboratory-scale flame treated earlier by Jeng et al. ${ }^{3}$ The same burner was used, with a burner exit Reynolds number of 11700 .

Predicted and measured spectral radiation intensities for the laboratory flame are plotted as a function of wavelength in Fig. 7. These results are for a horizontal path intersecting the flame axis at $x / d=100$. This position is near the maximum temperature position along the flame axis. Present measurements and those of Jeng et al. ${ }^{3}$ are illustrated on the figure, along with mean-property and stochastic predictions. The two sets of measurements and predictions all agree within the estimated uncertainties of the experiments $(10 \%)$.
The spectrum illustrated in Fig. 7 is dominated by the 1870 and $2700 \mathrm{~nm}$ bands of water vapor and the 2700 and $4300 \mathrm{~nm}$ bands of carbon dioxide. As noted earlier, spectral intensities are small between these bands, suggesting little continuum radiation from soot even though the flame appears yellow at this position. Differences between mean-property and stochastic predictions are small, suggesting little effect of turbulence/radiation interactions (e.g. stochastic predictions are roughly $10 \%$ higher than mean property predictions). The comparison between predictions and measurements is encouraging, similar to the earlier findings of Jeng et al. ${ }^{3}$

We now proceed with the radiative heat flux evaluation. As before, predictions were based on group-average conditions for the 100 and $200 \mathrm{MW}$ flames. Initial conditions for the following results were based on the momentum-velocity method. However, results using the divergent-nozzle method were essentially the same.

Predicted and measured radiative heat fluxes are summarized in Table 3 for the five heat flux detectors and seven flames. Since flame conditions varied within each group, experimental mean values and standard deviations are computed for each group to simplify comparison with predictions. Missing data in Table 3 represent conditions where records were not obtained due to instrumentation or data acquisition problems.

The average discrepancy between predictions and measurements in Table 3 is roughly $15 \%$, which is quite good in view of potential effects of flame disturbances due to ambient wind. Trends due to changes in burner conditions are also represented reasonably well. Two effects of this type deserve mention. First, detector 2 yields the lowest heat flux for the $100 \mathrm{MW}$ flames and the highest for the $200 \mathrm{MW}$ flames, probably due to the increase in flame length for the larger burner diameter since this is the highest detector (cf. Fig. 2). The predictions give the same trend. Second, detector 5 , which is directed vertically upward from the base of the flame, yields heat flux values

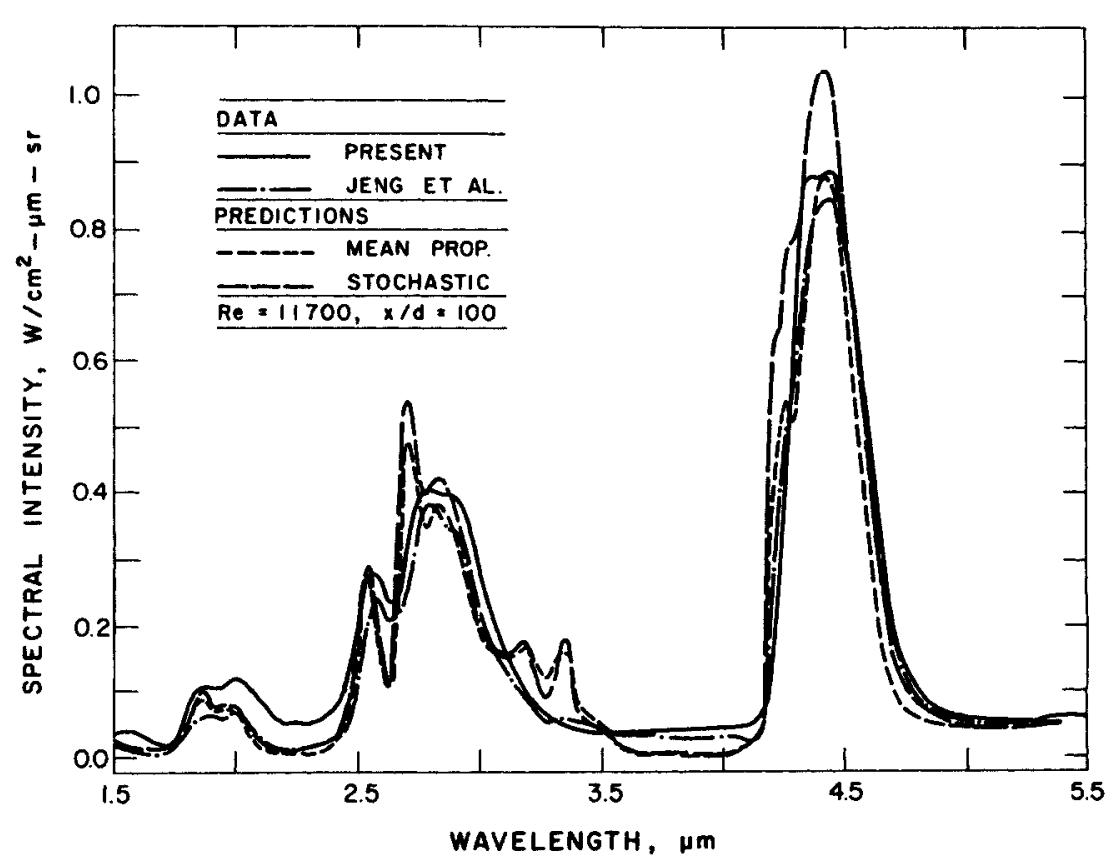

Figure 7. Spectral radiation intensities for natural gas/air diffusion flame at $x / d=100$. 


\begin{tabular}{lccccc}
\hline \multicolumn{5}{l}{ Table 3. Predicted and measured radiative heat fluxes $\left(\mathrm{kW} \mathrm{m}^{-2}\right)$} \\
Fiame & 1 & 2 & 3 & 4 & 5 \\
Detector & & & \\
$100 \mathrm{MW}$ flames & & & & & \\
1 & - & 3.17 & 4.75 & 5.89 & 8.32 \\
7 & 5.61 & 4.68 & 3.77 & 4.70 & 6.71 \\
Mean & 5.61 & 3.93 & 4.26 & 5.30 & 7.52 \\
Std dev. & - & 1.31 & 0.69 & 0.84 & 1.14 \\
Predictions & 4.83 & 3.03 & 3.85 & 5.67 & 5.26 \\
200 MW flames & & & & & \\
2 & 3.29 & - & - & 7.40 & 8.12 \\
3 & - & 8.79 & 6.37 & 7.98 & 9.11 \\
4 & 6.11 & 10.39 & 5.68 & 5.68 & 6.97 \\
5 & 5.51 & 8.29 & 4.99 & 5.77 & 7.08 \\
6 & 5.61 & 7.24 & 4.34 & 5.24 & 6.61 \\
Mean & 5.13 & 8.68 & 5.35 & 6.41 & 7.58 \\
Std dev. & 1.09 & 1.31 & 0.88 & 1.20 & 1.02 \\
Predictions & 5.17 & 6.82 & 4.49 & 6.68 & 5.24 \\
& & & & & \\
\hline
\end{tabular}

which are nearly the same for the 100 and $200 \mathrm{MW}$ flames. This trend is also reproduced by the predictions.

The fact that predictions in Table 3 generally underestimate measurements is expected. Recall that turbulence/radiation interactions, which were ignored during present heat flux computations, tend to increase radiation levels from mean property predictions by roughly $10 \%$ for methane/air diffusion flames. Wind disturbances, which deflected the flames toward the detector array, also contribute to higher measured radiative heat fluxes. The large-scale flames may also have some contribution to radiant heat fluxes due to continuum radiation from soot, which was ignored for present predictions. However, such contributions are clearly not large in comparison with other uncertainties of the present evaluation.

\section{CONCLUSIONS}

(1) Present theoretical methods for predicting the structure of turbulent diffusion flames, developed using data for well-controlled laboratory flames (flame heights $c a 1 \mathrm{~m}$ ), performed reasonably well when evaluated using data from large-scale natural gas/air diffusion flames (flame heights $c a 25 \mathrm{~m}$ ). Discrepancies between predicted and measured maximum mean temperatures along the axis were $200 \mathrm{~K}$, which is acceptable in view of anticipated effects of thermocouple errors and flame disturbances due to ambient winds, as well as lifting and external expansion effects near the injector.

(2) Predictions of radiative heat fluxes for the large-scale flames generally underestimated measurements on the order of $15 \%$, which is consistent with neglect of turbulence/radiation interactions and anticipated uncertainties of predictions and measurements.

(3) Although both large- and small-scale natural gas/air diffusion flames appear yellow over much of the visible portion of the flames, no evidence was found to suggest significant effects of continuum radiation from soot in these flames.

The present evaluation of the theoretical methods developed in References 1-8 was encouraging. However, additional evaluation using large-scale flames under more controlled conditions would be desirable. In particular, data providing initial conditions, species concentrations and spectral radiation intensities are needed for a more definitive test of analysis. Furthermore, present methods for treating underexpanded jet flames were relatively ad hoc and additional study of this phenomenon is warranted.

\section{Acknowledgements}

Theoretical portions of this investigation were supported by the Center for Fire Research of the National Bureau of Standards, Grant No. 60NANB5D0576, with Dr B. J. McCaffrey serving as NBS Scientific Officer. The authors also wish to thank J. Gregory and E. Tenneyson of the Minerals Management Services, DOI, for their continued interest in the experimental portion of the study.

\section{NOMENCLATURE}

$d \quad$ burner exit diameter

$d_{\mathrm{e}} \quad$ equivalent burner exit diameter

$g$ square of mixture fraction fluctuations

$G \quad$ mass velocity (flux)

$k$ turbulence kinetic energy

$\dot{m} \quad$ burner mass flow rate

$p, p^{0} \quad$ static and stagnation pressure

$\dot{Q}$ heat release rate

Re burner exit Reynolds number

$T, T^{0}$ static and stagnation temperature

$u \quad$ streamwise velocity

$u_{e}, u_{e}^{\prime}$ equivalent burner exit velocities $x \quad$ streamwise distance

$\varepsilon \quad$ rate of dissipation of turbulence kinetic energy

Subscripts
$0 \quad$ burner exit condition
$\infty$

$\infty \quad$ ambient condition

\section{Superscripts}

$\left(^{-}\right)$time-averaged property

( ) density weighted (Favre)-averaged property

\section{REFERENCES}

1. S.-M. Jeng, L.-D. Chen and G. M. Faeth, in Nineteenth Symposium (International) on Combustion, The Combustion Institute, Pittsburgh, Pennsylvania (1982), p. 349.
2. S.-M. Jeng and G. M. Faeth, J. Heat Trans, 106, 721 (1984)

3. S.-M. Jeng, M.-C. Lai and G. M. Faeth, Combust. Sci. and Tech. 40, 41 (1984). 
4. S.-M. Jeng and G. M. Faeth, J. Heat Trans. 106, 886 (1984).

5. S.-M. Jeng and G. M. Faeth, J. Heat Trans. 106, 891 (1984).

6. J.P. Gore, S.-M. Jeng and G. M. Faeth, Spectral and total radiation properties of turbulent carbon monoxide/air diffusion flames. AIAAJ (in press).

7. J.P. Gore, S.-M. Jeng and G. M. Faeth, Spectral and total radiation properties of turbulent hydrogen/air diffusion flames. $J$. Heat Trans. (in press).

8. J. P. Gore and G. M. Faeth, Structure and spectral radiation properties of turbulent ethylene/air diffusion flames, in TwentyFirst Symposium (International) on Combustion, The Combustion Institute, Pittsburgh, Pennsylvania (in press).

9. J.P. Gore, A theoretical and experimental study of turbulent flame radiation. PhD thesis, The Pennsylvania State University, University Park, Pennsylvania (1986).

10. D. Evans and D. Pfenning, Oil and Gas J. 83 (17), 80 (29 April 1985).

11. D. Pfenning, Blowout fire simulation tests. Report No. 84-4-208, Energy Analysis, Inc., Norman, Oklahoma (1984).

12. P. J. Kerney, G. M. Faeth and D. R. Olson, A/ChE. J. 18, 548 (1972).

13. J. C. Weimer, G. M. Faeth and D. R. Olson, A/ChE. J. 19, 552 (1973).

14. A. D. Birch, D. R. Brown, M. G. Dodson and F. Swaffield, Comb. Sci. and Tech. 36, 249 (1984).

15. B. C. R. Ewan and K. Moodie, Combust. Sci. and Tech. 45, 275 (1986).
16. R. W. Bilger, Prog. Energy Combust. Sci. 1, 87 (1976)

17. F. C. Lockwood and A. S. Naguib, Comb. and Flame 24, 109 (1975).

18. R. W. Bilger, Comb. Flame 30, 277 (1977).

19. S. Gordon and B. J. McBride, Computer Program for Calculation of Complex Chemical Equilibrium Compositions, Rocket Performance, Incident and Reflected Shocks and Chapman-Jouget Detonations, NASA SP-273 (1971).

20. C. B. Ludwig, W. Malkmus, J. E. Reardon and J. A. Thomson, Handbook of Infrared Radiation from Combustion Gases, NASA SP-3080 (1973).

21. W. L. Grosshandler, Int. J. Heat Mass Transfer 23, 1447 (1980).

22. F. C. Lockwood and N. B. Shah, in Eighteenth Symposium (International) on Combustion. The Combustion Institute, Pittsburgh, Pennsylvania (1981), p. 1405.

23. H. Tsuji and I. Yamaoka, in Eleventh Symposium (International) on Combustion, The Combustion Institute, Pittsburgh, Pennsylvania (1967), p. 970

24. H. Tsuji and I. Yamaoka, in Twelfth Symposium (International) on Combustion. The Combustion Institute, Pittsburgh, Pennsylvania (1969), p. 997.

25. H. Tsuji and I. Yamaoka, in Thirteenth Symposium (International) on Combustion, The Combustion Institute, Pittsburgh, Pennsylvania (1971), p. 723.

26. R. E. Mitchell, A. F. Sarofim and L. A. Clomberg, Comb. and Flame 37, 227 (1980) 